\section{$B D J$ at IADR}

The BDJ Portfolio had a booth (pictured) for three days at the recent IADR general session in Vancouver, Canada, a successful meeting attracting an estimated 5,000 delegates from around the world. It provided the opportunity to receive feedback from international readers and have detailed discussions with potential authors and researchers primarily for the $B D J$ and BDJ Open, both of which are clearly popular and seen as prestigious journals in which to be published.

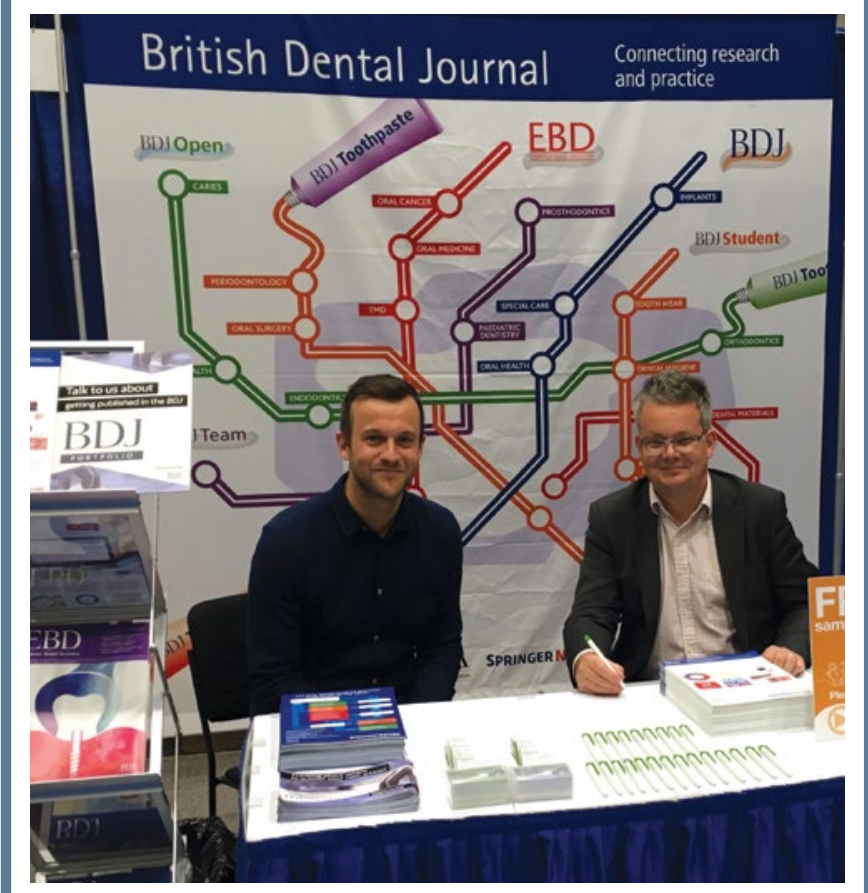

Editor Jonathan Coe (left) and Publisher James Sleigh, of the BDJ Portfolio, manning the $B D J$ stand at the IADR meeting in Vancouver

\section{BDA Indemnity now available}

The British Dental Association (BDA) is accepting applications for its new indemnity product, BDA Indemnity.

The unique offer, exclusively available to BDA members, provides long-term peace of mind, combining advice from a crack team of experienced dentists, with occurrence-based cover that provides real protection, no matter when the complaint comes in assuming the policy was in force at the time of treatment.

The policy provides a legally-binding right to cover, covers cases relating to both clinical work and personal conduct, and offers a flexible category structure so members only pay for the work they do. The product is designed to ensure policy holders will not subsidise the risks of other dentists or medical colleagues, or peers in other countries through their premiums. The policy does not cover oral and maxillofacial surgeons who carry out procedures within the scope of the specialty of oral and maxillofacial surgery, and who are registered with the GMC.

The policy is underwritten by market leaders Royal and Sun Alliance Insurance plc.

BDA Managing Director Peter Ward said: 'This is a landmark event for the Association, and the profession it serves. We are now putting indemnity cover at the very heart of our mission to support UK dentists. The profession can now benefit from a unique indemnity package designed by and for dentists. Our expert team are now ready to take your calls.'

More information can be found at https://www.bda.org/ indemnity.

\title{
Double honours for Helen in Vancouver
}

The International Association for Dental Research (IADR) announced Helen Whelton, University College Cork, Ireland, as the 2019 recipient of the Distinguished Scientist H. Trendley Dean Memorial Award and the 2019 recipient of the IADR E.W. Borrow Memorial Award, at the IADR/ AADR/CADR General Session \& Exhibition held in Vancouver in June.

Professor Whelton, who served as the $90^{\text {th }}$ President of IADR from 2013-14, is the Head of the College of Medicine and Health at University College Cork, Ireland, and Chief Academic Officer for the South Southwest Hospital Group. Her research focus has been on fluoride and health services research.

The IADR Distinguished Scientist H. Trendley Dean Memorial Award, one of the 17 IADR Distinguished Scientist Awards, was created in memory of $\mathrm{H}$. Trendley Dean, the $21^{\text {st }}$ President of the IADR and first dental officer of the National Institutes of Health. The award consists of a monetary award and plaque and is given for meritorious research in epidemiology and public health. It is one of the highest honours bestowed by IADR.

Sponsored by The Borrow Foundation, the IADR E.W. Borrow Memorial Award recognises and stimulates research in oral health

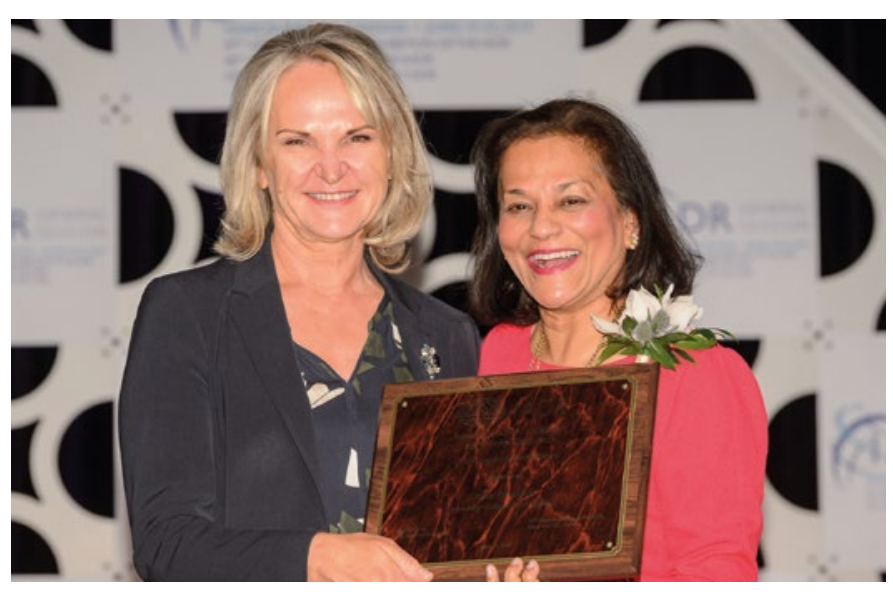

Helen Whelton (left) with IADR President Rena D'Souza

prevention for children, with a priority for caries prevention where fluoride in different formats is used. This is the $28^{\text {th }}$ year of the IADR E.W. Borrow Memorial Award, which consists of a plaque and a monetary award of $\$ 3,500$. 